Research Article

\title{
Research on Dynamic Characteristics and Compensation of Wire Rope Tension and Load Measurement Based on Hydraulic Connection Device
}

\author{
Di Song $\mathbb{D},{ }^{1,2}$ Gui-Yun Xu $\mathbb{D}^{1},{ }^{1}$ Gao-Yang Lei $\mathbb{D}^{1},{ }^{1}$ Xiao-Guang Zhang $\mathbb{D}^{1,2}$ \\ and Bao-Lai Tian ${ }^{1}$ \\ ${ }^{1}$ School of Mechanical and Electrical Engineering, China University of Mining \& Technology, Xuzhou 221116, China \\ ${ }^{2}$ Jiangsu Engineering Technology Research Center on Intelligent Equipment for Fully Mining and Excavating, \\ Xuzhou 221116, China
}

Correspondence should be addressed to Gui-Yun Xu; xgyzxgl@163.com and Gao-Yang Lei; lgy767081515@163.com

Received 8 October 2018; Revised 7 February 2019; Accepted 28 March 2019; Published 16 May 2019

Academic Editor: Chao Tao

Copyright $\odot 2019$ Di Song et al. This is an open access article distributed under the Creative Commons Attribution License, which permits unrestricted use, distribution, and reproduction in any medium, provided the original work is properly cited.

During the operation of hoist, the speed and acceleration of each wire rope are inconsistent and the inertia force is changed due to the wear of the friction pad on the drum, which makes an impact on the cylinder of the tension balance hydraulic connection device and aggravates the flow pressure loss. It results in the nonlinear friction force between the piston and cylinder and affects the accuracy of wire rope tension and load measured by an oil pressure sensor which is installed on the tension balance hydraulic connecting device. In this paper, the simulation model of the tension balanced hydraulic connecting device is established by AMESim software, and the hydraulic dynamic response under different pressures, flow rates, and speed of a single hydraulic cylinder and tension balanced hydraulic connecting device is analyzed. The Leuven friction model is used to compensate the pressure loss along the course and local pressure loss and calculate the friction force, where specific parameters are determined by experiments. The real-time compensation experiment of the tension balance hydraulic connecting device proves that the device effectively improves the accuracy of wire rope tension and load monitoring.

\section{Introduction}

The hoist is an important part of the mine hoisting system which can be divided into single winding type and multirope friction type, and multirope friction hoist is most widely used in coal mines at present $[1,2]$. To maintain the safe operation of the hoist, it is necessary to measure the wire rope tension and load.

In the paper, the wire rope tension and load can be measured by the oil pressure sensor installed on the tension balance hydraulic connection device, which is connected with the hoisting container and the wire ropes of multirope friction hoist [3]. The structure of tension balance hydraulic connection device is shown in Figure 1(a). The device is composed of four separate tension measuring devices, which are connected together by connecting device composed of tubing and valves [4]. Oil pressure sensors are installed on each cylinder of tension measuring devices by external hydraulic pipelines to monitor oil pressure. The oil pressure of each cylinder multiplied by the working area of the piston can be conversed to the tension of each wire rope $[5,6]$. Initially, the pressure of each cylinder keeps equal. When the tension of each wire rope is inconsistent due to the different elongation of each rope, the pressure balance of each cylinder is broken. The wire rope with the maximum tension is greater than the initial pressure, and this wire rope will first pull the piston rod to increase the wire rope length and then reduce the tension. Then, the oil in the maximum pressure cylinder passes through connecting device to the minimum pressure cylinder, which pushes the piston rod, reduces the length of the wire rope, and increases the tension. Finally, the tension of each wire rope and the pressure of each cylinder are equal. Therefore, the device can balance the tension of each wire rope and buffer the vibration and impact of the wire rope [7]. 


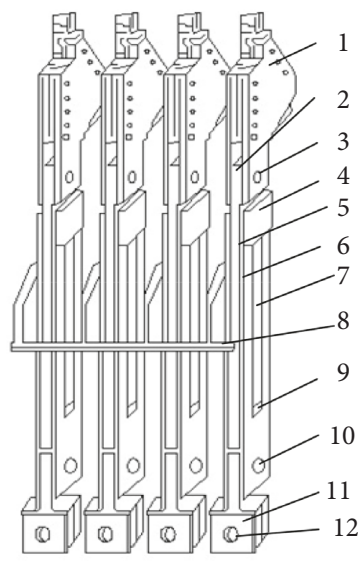

(a)

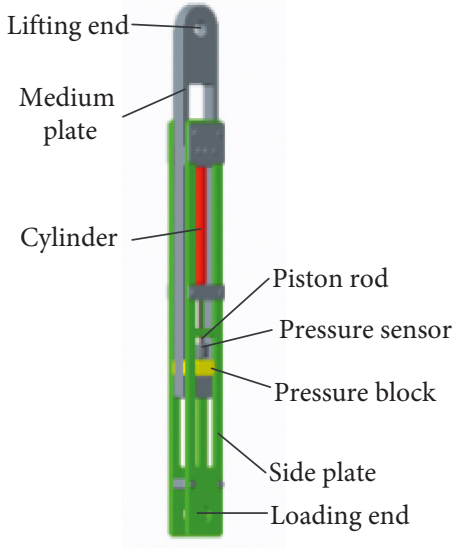

(b)

FIGURE 1: Structure of wire rope tension balance hydraulic connection device. 1, wedge-shaped rope ring; 2 , medium plate; 3 , top connecting pin; 4, baffle; 5, pressure plate; 6 , side plate; 7, connecting cylinder; 8 , connecting device; 9 , pressure block; 10, middle connecting pin; 11 , reversing fork; 12 , connecting pin.

Domestic and foreign scholars have done a lot of work on monitoring the wire rope tension and load. In foreign countries, the wire rope tension and load measurement method measured by the sensor or other instruments have been developed in many countries [8-10]. O'Dogherty [11] designed an octagonal ring dynamometer to measure two orthogonal forces and a moment applied in the plane of the ring through appropriately mounted strain gauge bridges and presented a fundamental formulate for the moment and strain distributions in circular, octagonal, and extended octagonal rings. In 2012, Jin and Zhang [12] designed a tension sensor for the hoist wire rope using the strain gauge as the measurement principle and the spoke as the flexible structure and adopted configuration software as detection system software to realize online monitoring of the tension. Daifuku et al. [6] developed a tension meter for wire rope and lashing belt of a postmountable type by which the magnitude of their tension in use can be evaluated. Zhang and Sun [13] used the method of variables separation and generalized coordinates method to analyze the characteristics of the mine hoist wire rope tension and designed a steel rope tension online monitoring system. Fan and Yang [14] derived the calculation formula of wire-rope tension based on inhomogeneous chord vibration and developed the test method of hoist wire-rope tension by using the basic principles of the wire-rope tension measurement with method of vibration.

For measuring the wire rope tension and load by installing oil sensors on a hydraulic balancing device, there are usually two methods: conversing tension to pressure and measuring oil pressure directly $[15,16]$. The former method measures the pressure between the piston rod and the pressure block and converts the tension of the wire rope into pressure, which is shown in Figure 1(b). However, the results measured by this method have severe fluctuation and noise, which cannot effectively reflect the tension and load. In this paper, oil pressure sensor installed in tension balance hydraulic connection device is used to measure the wire rope tension and load, which can effectively reduce fluctuation of wire rope. The wire rope tension and load can be measured accurately by the effective compensation of the oil pressure and friction force through the Leuven friction model [17].

\section{Mathematical Model and Dynamic Response of the Connection Device}

2.1. Mathematical Model of the Hydraulic Connection. When the influence of wire rope mass on tension is neglected, the wire rope and the hydraulic connecting device can be regarded as a spring-damper system without mass, in which the wire rope is regarded as a spring system and the hydraulic cylinder of the hydraulic connecting device is regarded as a damper system. The system is shown in Figure 2.

$c^{\prime}$ represents the damping coefficient of liquid flow in the pipeline, $a$ denotes the acceleration, $c$ represents the damping coefficient of piston movement, $x_{i}$ denotes the displacement of piston in the $i$ hydraulic cylinder relative to the initial position of piston, $F_{i}$ denotes the force of the piston rod of the hydraulic cylinder, $m$ represents the mass of the piston, $m_{2}$ represents the mass of hydraulic cylinder body, $p_{i}$ is the pressure of the rod free cavity, and $P_{i}$ is the force of hydraulic cylinder body caused by lifting load. Take one of the hydraulic cylinders as an example:

The dynamic equation of piston force can be described as follows:

$$
m a=F_{i}-p_{i} A-c \dot{x}_{i} .
$$

When the hydraulic cylinder piston mass $m$ is ignored, equation (1) can be described as follows:

$$
F_{i}=p_{i} A+c \dot{x}_{i}
$$

The dynamic equation of hydraulic cylinder body force can be described as follows:

$$
m_{2} \ddot{x}^{\prime}=p_{i} A-P_{i}+c \dot{x}_{i} \text {. }
$$

When the hydraulic cylinder body mass $m_{2}$ is ignored, equation (3) can be described as follows: 


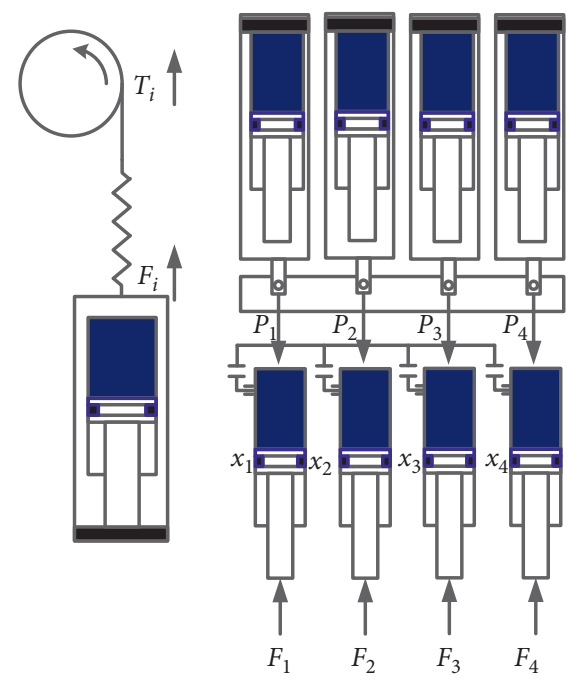

Figure 2: Mathematical model of the hydraulic connection.

$$
P_{i}=p_{i} A+c \dot{x}_{i}
$$

Through equation (2) and equation (4), there is an approximate equality between the tension of the wire rope and the lifting load during the operation of the hoisting system.

\subsection{Hydraulic Dynamic Response of the Hydraulic Connection} Device. When the tension of each wire rope is not equal, the displacement of the corresponding cylinder piston and the pressure of the working chamber are changed. When the tension is adjusted by the hydraulic connecting device, the oil in the cylinder will flow from the high-pressure cylinder to the low-pressure one, which causes pressure impact during the flow passing through the pipeline and valve. Taking the parallel connection of two cylinders as an example, the pressure of two cylinders is $p_{1}, p_{2}$ and the volume is $V_{1}, V_{2}$. The continuity equation of flowing oil is expressed as follows:

$$
\begin{aligned}
& \frac{d V_{2}}{d t}=\frac{V_{2}}{\beta} \frac{d p_{2}}{d t}, \\
& \frac{d V_{2}}{d t}=a \bar{u},
\end{aligned}
$$

where $a$ means the average cross-sectional area of pipes and $F=\sigma_{0} z+\sigma_{1}(d z / d t)+\sigma_{2} v$ denotes the velocity of flowing oil in pipeline. According to Poiseuille formula, the friction resistance of pipeline in laminar flow state is as follows:

$$
f=\frac{128 \mu l}{\pi d^{4}} a^{2} u
$$

where $\mu$ represents fluid viscosity, $d$ means average pipe diameter, and $l$ denotes the pipe length. The equation of liquid force in parallel pipes is as follows:

$$
\rho a l \frac{d \bar{u}}{d t}=p_{1} a-p_{2} a-f .
$$

Combining equations (5)-(7), the following equation can be obtained:

$$
\frac{4 \rho l V_{2}}{\pi \beta d^{2}} \frac{d^{2} p_{2}}{d t^{2}}+\frac{128 \mu l V_{2}}{\pi \beta d^{4}} \frac{d p_{2}}{d t}+p_{2}=p_{1},
$$

where $\rho$ represents oil density in the cylinder and $\beta$ means liquid bulk modulus. This is a typical two-order vibration. The natural frequency of the system is as follows:

$$
w_{n}=\frac{d}{2} \sqrt{\frac{\pi \beta}{\rho l V_{2}}} \text {. }
$$

The damping ratio of the system is

$$
\xi=\frac{32 u}{d^{3}} \sqrt{\frac{V_{2} l}{\pi d \beta}}
$$

The typical transfer function of the two order system is

$$
G(s)=\frac{P_{2}(s)}{P_{1}(s)}=\frac{1}{\left(1 / w_{n}\right) s^{2}+\left(2 \xi / w_{n}\right) s+1} .
$$

In the simulation, the density, kinematic viscosity, piston diameter, cylinder length, spool diameter, pipeline length, and dynamic viscosity are $900 \mathrm{~kg} / \mathrm{m}^{3}, 46 \mathrm{~mm}^{2} / \mathrm{s}, 80 \mathrm{~mm}$, $800 \mathrm{~mm}, 6 \mathrm{~mm}, 1000 \mathrm{~mm}$, and $0.0414 \mathrm{~kg} / \mathrm{ms}$, respectively. The Bode diagram is shown in Figure 3.

According to the above equations and Figure $3, w_{n}$ increases with the decrease of the length $(l)$ of the pipeline and the volume $\left(V_{2}\right)$ and the increase of the diameter $(d)$ of the pipeline. Adjusting these three parameters can promote the natural frequency and the damping ratio of the system. In order to improve the stability of hydraulic connecting device in the damped second-order oscillation system, the resonance frequency should be avoided as far as possible.

\section{Simulation of Hydraulic Connection Device}

The hydraulic model of single hydraulic system and hydraulic connecting device are established and simulated by using AMESim under the influence of drum and tail rope. The dynamic characteristics of hydraulic connecting device are analyzed under different pressure and flow rate, and the effects of load change on the pressure, flow, and flow rate of connecting device are studied [18]. It can reflect the influence of wire rope vibration on the measurement of tension and load and pave the way for the selection of compensation model for compensating the loss of pressure and flow [19].

\subsection{Modeling and Simulation Results of Single Hydraulic System}

3.1.1. AMESim Modeling of Single Hydraulic System. In Figure 4, it can be seen that the hydraulic simulation system consists of electromagnetic directional valve, hydraulic cylinder, and overflow valves in the return circuit of the oil. The load can be simulated by adjusting the pressure of the overflow valves.

In the simulation, the rated pressure of the pump is $12 \mathrm{MPa}$ and the rated flow rate is $20 \mathrm{~L} / \mathrm{min}$, and the actual flow rate is adjusted as required. The hydraulic cylinder is $\phi 100 \mathrm{~mm} \times \phi 60 \mathrm{~mm} \times 1000 \mathrm{~mm}$. 


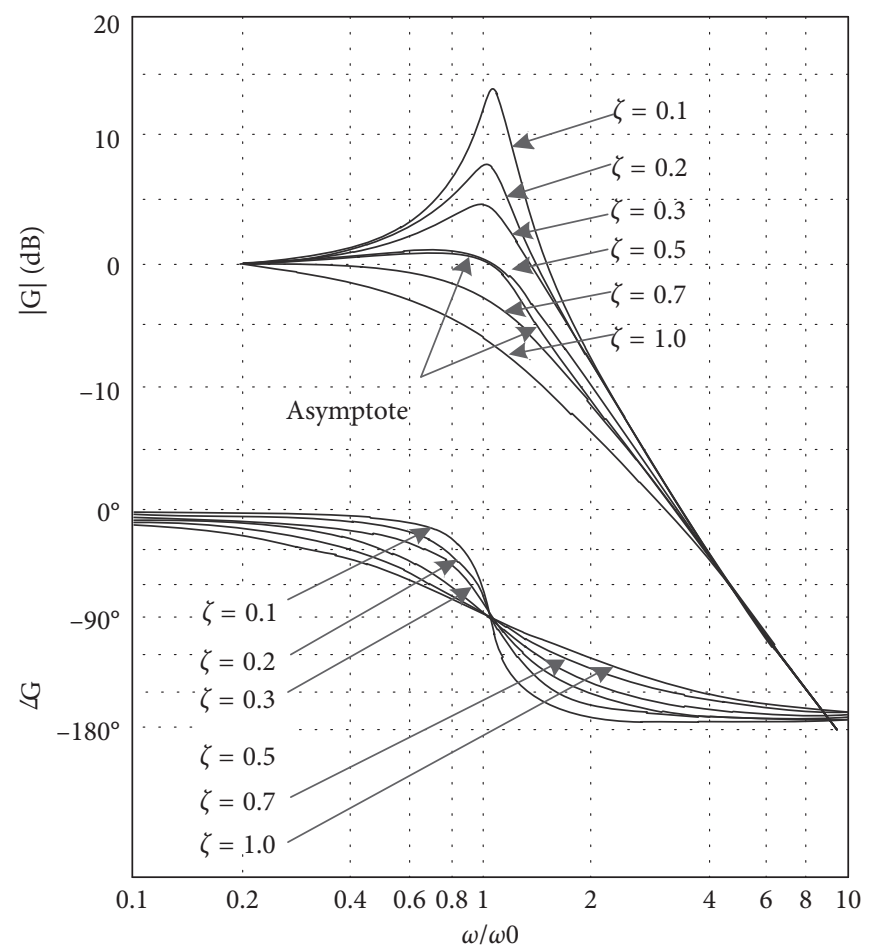

Figure 3: Bode diagram.

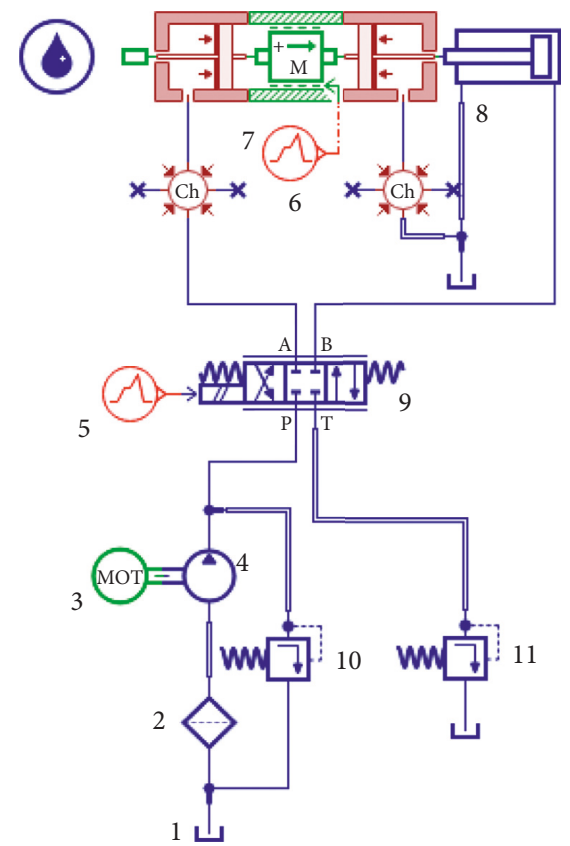

Figure 4: AMESim modeling of the single hydraulic system. 1, oil tank; 2, oil filter; 3 , motor; 4 , hydraulic pump; 5 , signal source $1 ; 6$, signal source $2 ; 7$, balance cylinder; 8 , loading cylinder; 9 , electromagnetic directional valve; 10 , overflow valve $1 ; 11$, overflow valve 2 .

\subsubsection{Simulation of Shuttling of Single Hydraulic Cylinder}

(1) The pressure characteristics of hydraulic cylinders under different load pressures.

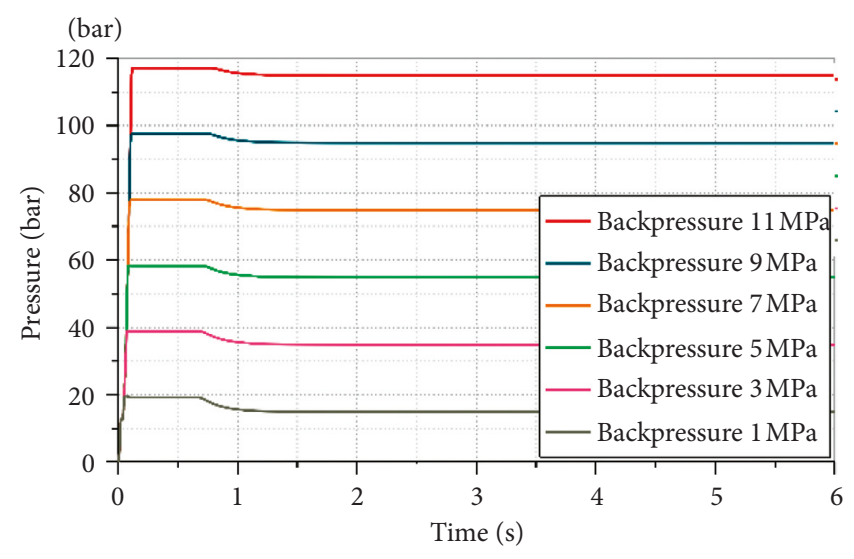

FIgURE 5: Pressure changes of the cylinder without rod chamber.

The load pressure is set to $11 \mathrm{MPa}, 9 \mathrm{MPa}, 7 \mathrm{MPa}$, $5 \mathrm{MPa}, 3 \mathrm{MPa}$, and $1 \mathrm{MPa}$, respectively, through the different backpressure of overflow valves in the return circuit of the oil. According to Figure 5, the pressure loss under different backpressure conditions is $0.36 \mathrm{Mpa}$, which is independent of working pressure. Taking the backpressure curve of $11 \mathrm{MPa}$ as an example, the maximum fluctuation pressure is $11.86 \mathrm{MPa}$ during $0.2 \mathrm{~s}$ and the pressure is stable at $11.36 \mathrm{MPa}$ after $0.3 \mathrm{~s}$. The stable pressure is larger by $0.36 \mathrm{MPa}$ than the backpressure load pressure, which is the pressure loss.

There is friction resistance in the piston of the balancing cylinder, which influents the pressure. In Figure 6, it is shown that when the friction becomes 


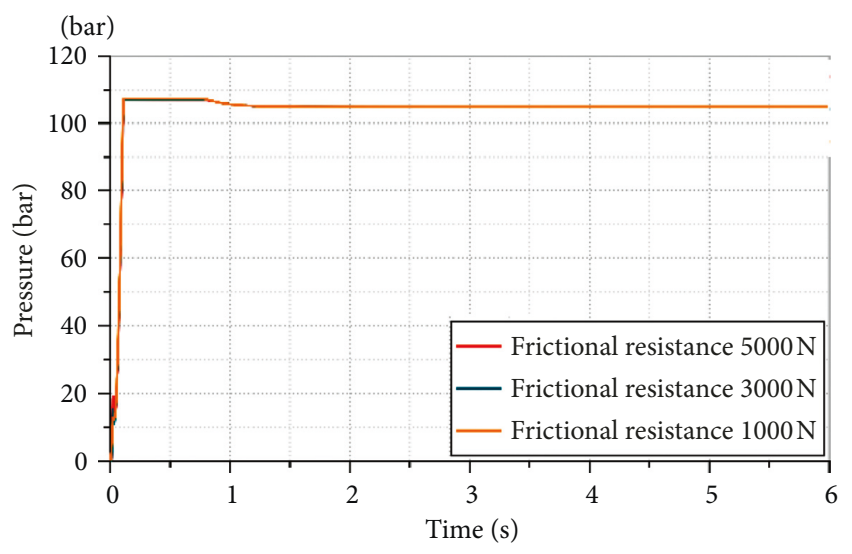

(a)

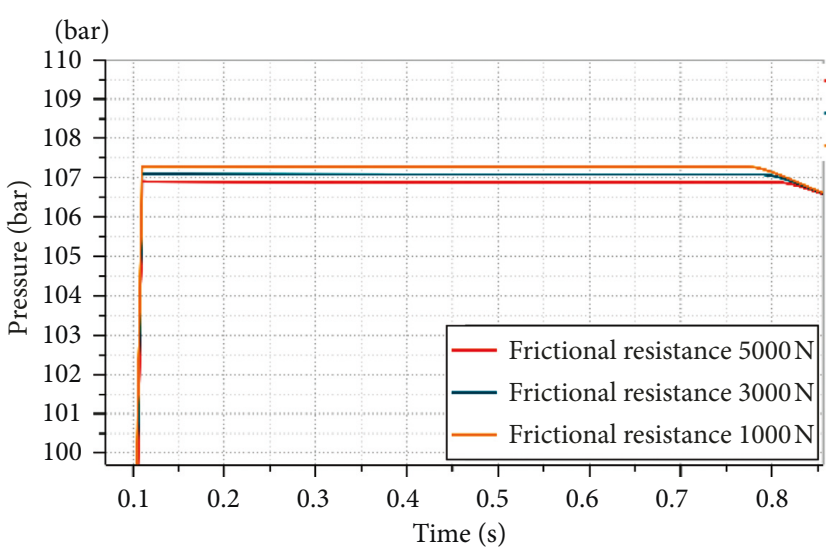

(b)

FIGURE 6: Effect of frictional resistance on the pressure of the rodless cavity.

smaller, the pressure fluctuation and the fluctuation time become greater and longer.

(2) The pressure characteristics of hydraulic cylinder under different flow rate.

The flow rate of the hydraulic pump is set to $20 \mathrm{~L} /$ $\mathrm{min}, 15 \mathrm{~L} / \mathrm{min}, 10 \mathrm{~L} / \mathrm{min}$, and $5 \mathrm{~L} / \mathrm{min}$, respectively, with the $10 \mathrm{MPa}$ load pressure.

Figure 7 shows that the pressure loss varies with flow rate. The pressure fluctuation amplitude of cylinder is proportional to the flow rate of the hydraulic pump, and the time required to balance the pressure in the cylinder to reach the load pressure is inversely proportional to it.

(3) The pressure characteristics of the hydraulic cylinder under reciprocating motion.

The motion direction of the piston of the cylinder changes irregularly under actual working conditions. The pressure of cylinder is affected by the change of piston direction with the frictional resistance of the cylinder.

According to Figure 8, the two curves in the diagram are the simulation of two cases: frictional resistance exists or not. The pressure of cylinder cavity fluctuates when the cylinder reverses at $1 \mathrm{~s}$ and $2 \mathrm{~s}$.

\subsection{Modeling and Simulation Results of Hydraulic Connection Device}

3.2.1. Modeling of Hydraulic Connection Device. In Figure 9, the hydraulic connection device is established by using AMESim, where the friction wheel is a standard circle. In order to simulate the excitation of different wear of four rope grooves of driving drum on hoist wire rope, the excitation change caused by the wear of the liner is transformed into the force excitation in the vertical direction of the connecting device.

\subsubsection{Simulation Analysis of Hydraulic Connection Device.} When the hydraulic connecting device works, the oil pressure and flow impact occur in the pipeline inevitably. It

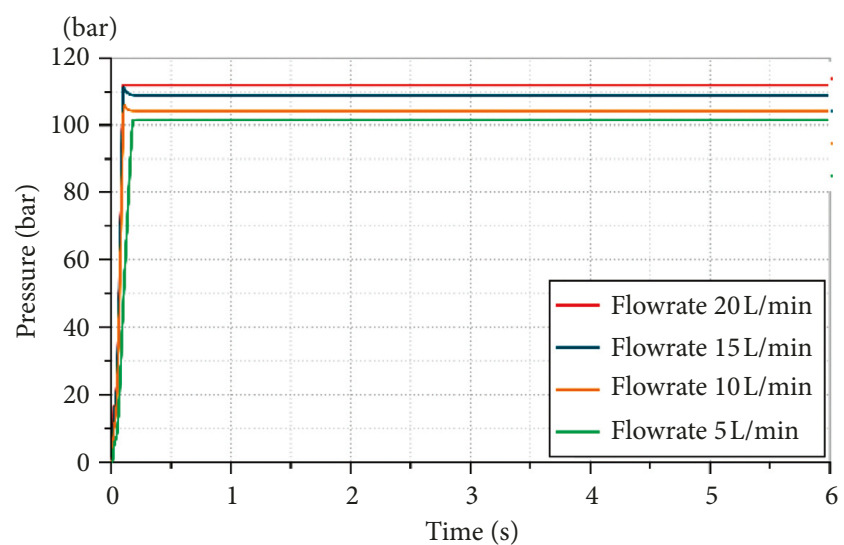

FIgURE 7: Pressure curves of rodless cavity under different flow rates.

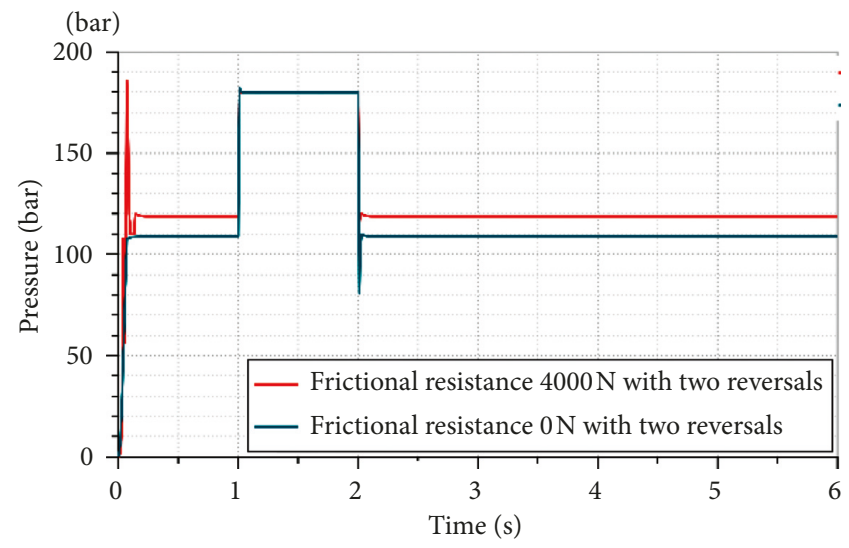

Figure 8: Pressure changes under frictional resistance.

brings a great impact on the stability of the hydraulic system and the accuracy of wire rope load detection.

(1) Figure 10 shows the input curve of four balancing cylinder signal load sources. The four load signals of $0 \sim 3 \mathrm{~s}$ increase from around $2000 \mathrm{~N}$ to about $5000 \mathrm{~N}$ 


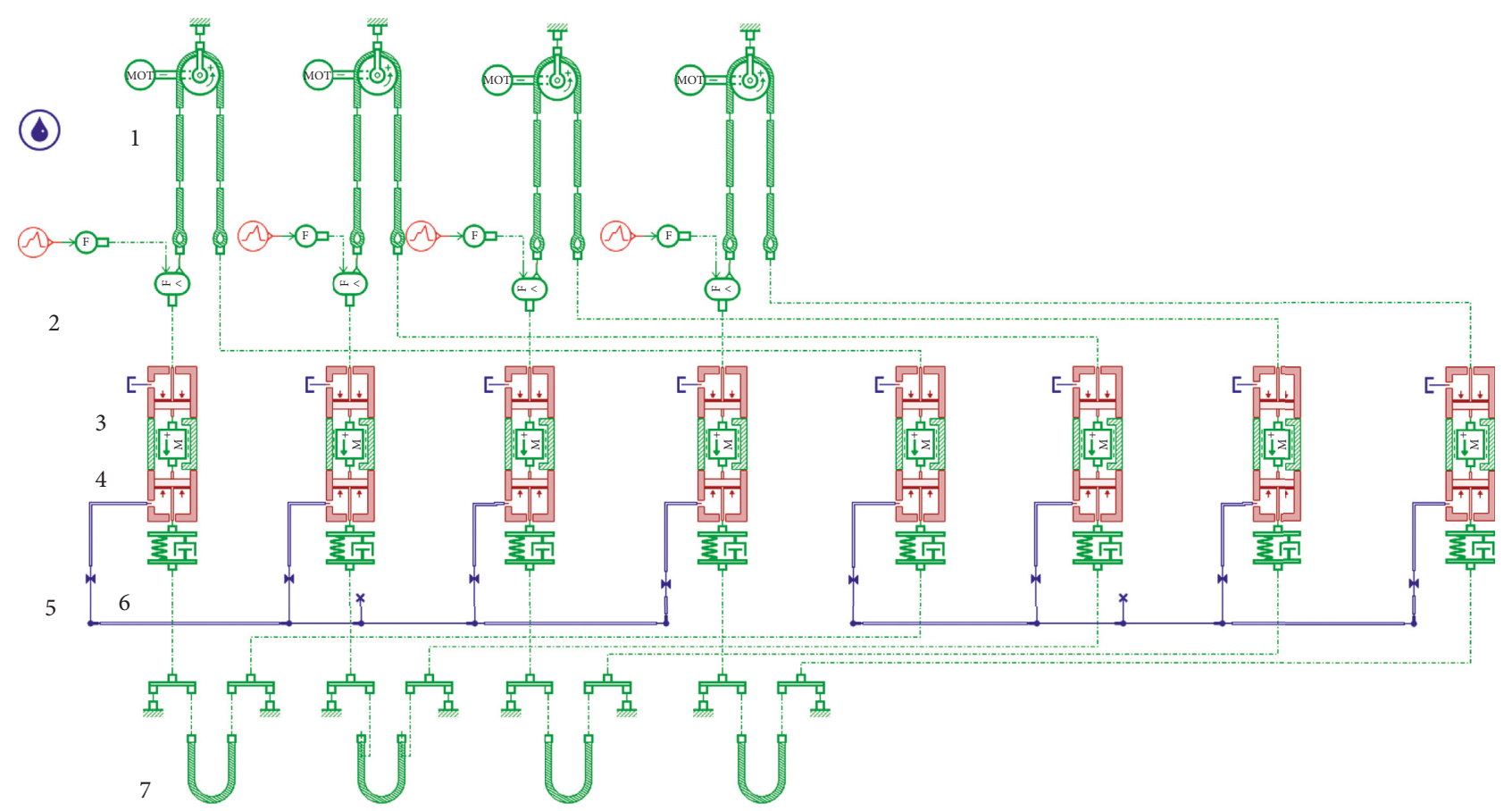

FIGURE 9: Simulation of the hydraulic connection device. 1, roller; 2, load signal source; 3, balancing cylinder; 4, friction mass block; 5 , stop valve; 6 , spring damping; 7 , tail rope.

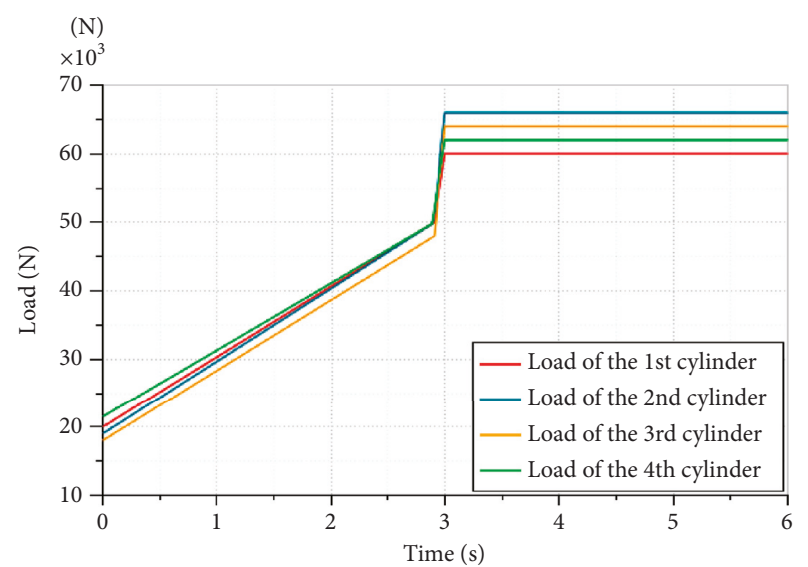

Figure 10: Input curve of signal source load.

in different slopes. The load changes suddenly to more than $6000 \mathrm{~N}$ at $3 \mathrm{~s}$ and remains unchanged later.

(2) The characteristic of oil tube is not considered. After removing all the stop valves 5 in the simulation model of Figure 9, the simulation curve of the four cylinders without rod chamber is shown in Figure 11. It shows that no matter how load changes, the pressure in the four balanced cylinders keeps the same.

(3) The characteristic of oil tube is considered. There is a stop valve on each bypass oil tube of the connecting device in Figure 9. The pressure changing curve of hydraulic cylinder without rod chamber in connection device is shown in Figure 12. Comparing with the load signal of Figure 10, the hydraulic oil pressures in the four

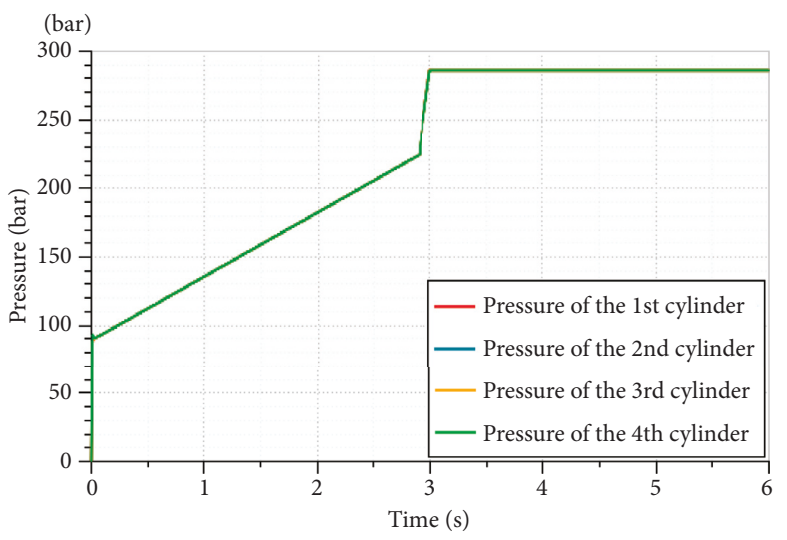

Figure 11: Pressure of four cylinders without rod chamber.

cylinders without rod chamber in Figure 12(a) are adjusted by the connecting device and maintained the same.

However, it can be seen from the Figure 12(b) that when the load changes suddenly, it will impact the balance cylinder and cause the difference pressure in the cylinder instantly. It can be regarded as a difference between the loads of the four wire ropes. According to the Figure 12(b), the fluctuation is the largest at $3.1 \mathrm{~s}$ time, and then the cylinder pressure remains stable. The pressure impact of hydraulic cylinder cannot be ignored, which affects the dynamic performance of cylinder and the accuracy of load detection.

(4) Figure 13 shows the flow rate curve of hydraulic cylinder without rod chamber in the connection device. The flow of the first and the third cylinders 


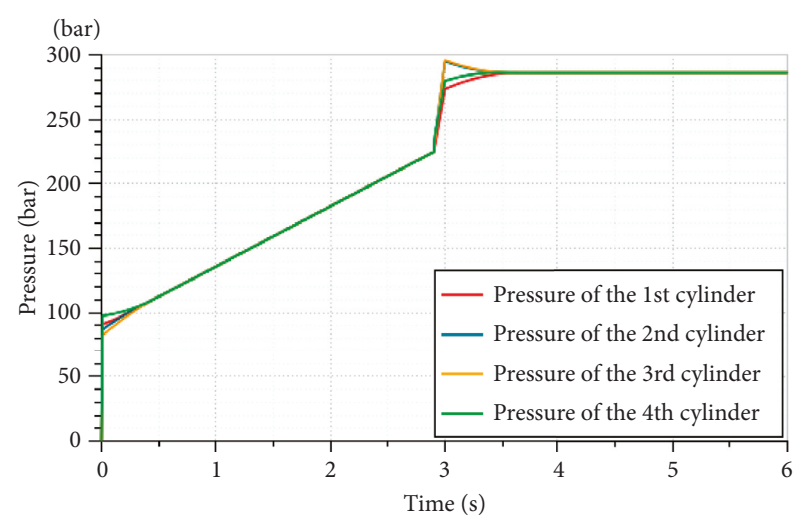

(a)

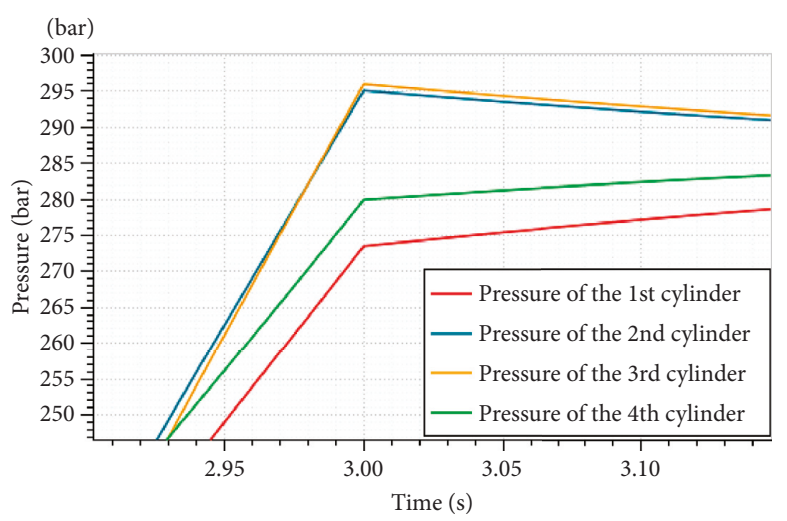

(b)

Figure 12: Pressure variation curves of each hydraulic cylinder without rod chamber in the connection device.

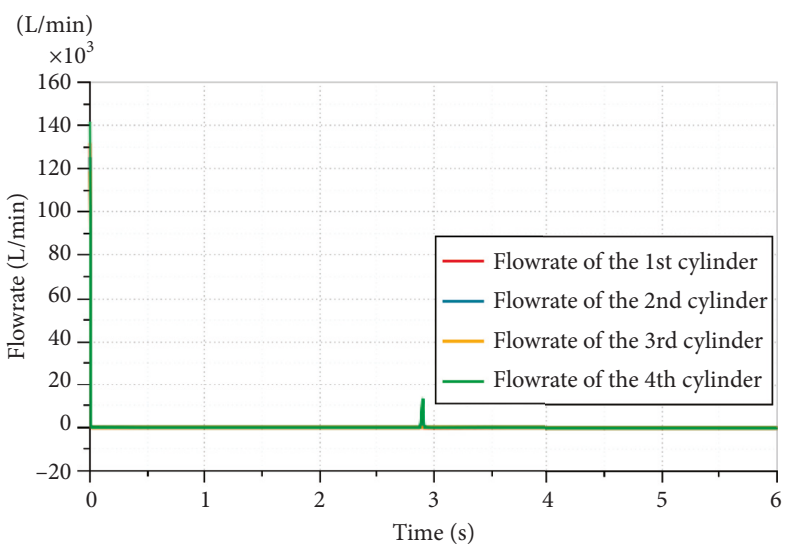

(a)

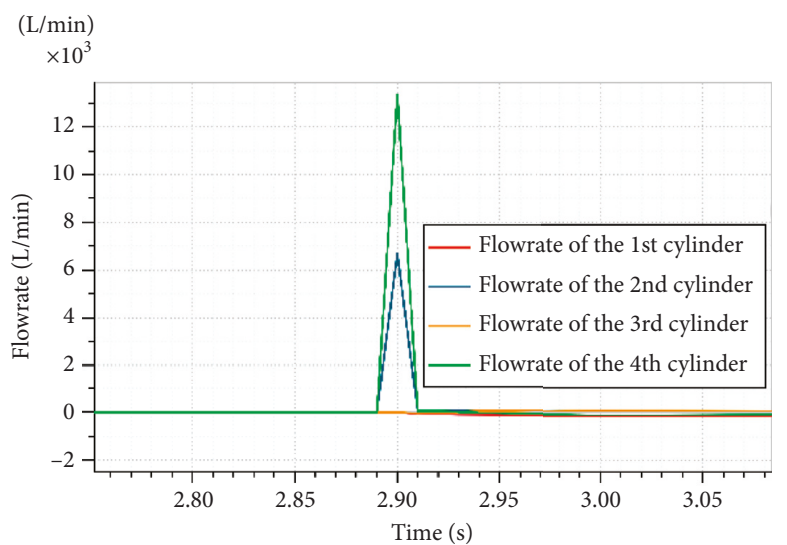

(b)

FIgURe 13: Flow rate curve of the hydraulic cylinder without rod chamber in the connection device.

vary during $2.88 \mathrm{~s}$ to $3.01 \mathrm{~s}$. The flow of the first and the third cylinder decreases first and then increases. The flow of the second cylinder and the fourth cylinder varies greatly and becomes unstable during $2.88 \mathrm{~s}$ to $3.01 \mathrm{~s}$. It is explained that pressure shock is the main cause of the flow change in the rodless chamber.

(5) Figure 14 shows the changing displacement curve of four balancing cylinders in the hydraulic connecting device. Because the load of the first cylinder and the fourth cylinder is larger during $0 \mathrm{~s}$ to $3 \mathrm{~s}$, the cylinder produces positive movement and the hydraulic oil discharges. The piston displacements of the four cylinders are $10 \mathrm{~mm},-10 \mathrm{~mm}$, $-18 \mathrm{~mm}$, and $20 \mathrm{~mm}$, respectively. When the load is changed suddenly during $3 \mathrm{~s}$ to $6 \mathrm{~s}$, the load of the second cylinder is the largest and the load of the first cylinder is the smallest. Therefore, the piston of the fourth cylinder produces the maximum displacement of $26 \mathrm{~mm}$. The displacement of the third and fourth cylinders is $10 \mathrm{~mm}$ and $-10 \mathrm{~mm}$, and the displacement of the first cylinder is $-26 \mathrm{~mm}$.

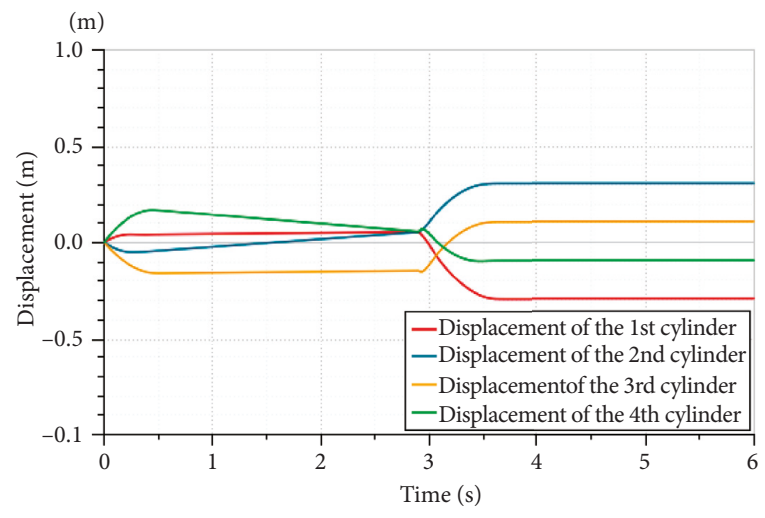

FIgURe 14: Displacement curve of the cylinder piston.

Comparing with the curve of signal source load in Figure 10, when the load changes drastically during $0-0.2 \mathrm{~s}$ and 2.8-3.4 s, it will cause a greater pressure impact to the hydraulic connecting device. If the loads of the four cylinders are obviously different, the pressure of the four cylinders are adjusted by connecting pipelines to ensure the same internal pressure of the rodless chamber, which is shown in Figure 12. 
The dynamic characteristics of the hydraulic balancing device show that it plays an important role of balancing oil pressure, wire tension, and load to a certain extent. It seriously affects the accurate monitoring of wire rope load which is affected by the load changing, the friction between piston and hydraulic, and the pressure loss caused by hydraulic flow.

\section{Pressure and Friction Compensation of Hydraulic Connection Device}

4.1. Pressure Loss. The viscous fluid flowing in the pipeline will be resisted and the energy will be lost due to liquid inductance, resistance, and capacitance of viscous fluid. The loss mainly includes pressure lost along the pipeline and local pressure loss [20]. The pressure lost along the pipeline refers to the pressure loss caused by the viscous force during fluid flowing through the straight pipe; the local pressure loss refers to the pressure loss caused by the sudden diameter change or bending of the pipe.

The pressure lost along the pipeline can be described as follows:

$$
\Delta p_{f}=\lambda \frac{l}{d} \frac{\rho v^{2}}{2}
$$

where $\lambda$ represents the pressure coefficient along the pipeline, $l$ means the length of the pipe, $d$ means the inner diameter of the pipe, $\rho$ denotes the liquid density, and $v$ represents the average velocity of the liquid.

The local pressure loss can be described as follows:

$$
\Delta p_{r}=\xi \frac{\rho v^{2}}{2}
$$

where $\xi$ represents the local resistance coefficient, which is related to the shape of pipe fittings and the Reynolds number Re.

The total pressure loss can be expressed as follows:

$$
\Delta p=\Delta p_{f}+\Delta p_{r}
$$

4.2. Friction Compensation Model. Sliding hysteresis friction force in the hydraulic cylinder is the main factor affecting the monitoring results [21]. Under the condition of tangential force, elastic deformation produces frictional force. When the force increases to a certain value, the sliding phenomenon appears. At the same time, it also shows viscous sliding, friction hysteresis, and presliding displacement, which are suitable for dynamic friction model. The Leuven friction model based on elastic bristle contact not only contains the friction characteristics of common LuGre friction model, but also uses hysteresis function with nonlocal memory to build more accurate model of each cylinder. The Leuven friction model is adopted for the hydraulic cylinder seal. The relationship between oil pressure and parameters in the Leuven friction model is fitted by the friction compensation test and the parameters of the Leuven friction model are estimated by curve fitting [22].

The Leuven friction model [17] can be described as follows:

$$
\left\{\begin{array}{l}
\frac{d z}{d t}=v-\frac{\sigma_{0}}{g(v)} z|v|, \\
f=\sigma_{0} z+\sigma_{1} \frac{d z}{d t}+\sigma_{2} v, \\
g(v)=f_{\mathrm{c}}+\left(f_{\mathrm{s}}-f_{\mathrm{c}}\right) * e^{-\left(v / v_{\mathrm{s}}\right)^{2}},
\end{array}\right.
$$

where $v$ represents the relative velocity of the friction surface, $z$ means the relative axial deformation between the sealing ring and the moving surface under viscous condition, $\sigma_{0}$ denotes the axial stiffness coefficient of the sealing ring, $\sigma_{1}$ represents the axial damping coefficient of the sealing ring, $\sigma_{2}$ means the viscous friction coefficient of the system, $f_{\mathrm{c}}$ represents the Coulomb friction, $f_{\mathrm{s}}$ means the maximum static friction, $v_{\mathrm{s}}$ denotes the critical speed, and $g(v)$ describes the Stribeck Effect.

When the system stability $z=0$, the following equation can be deduced:

$$
F_{\mathrm{fs}}(v)=\left[F_{\mathrm{c}}+\left(F_{\mathrm{s}}-F_{\mathrm{c}}\right) e^{-\left|v / v_{\mathrm{s}}\right|^{2}}\right] \operatorname{sgn}(v)+K_{\mathrm{v}} v,
$$

where $K_{\mathrm{v}}$ means the viscous friction coefficient of the system.

4.2.1. Friction Compensation Test. The test rig of friction compensation is shown in Figure 15, including friction compensation test stand, oil supply device, and display screen. When the oil enters the rodless cavity through the oil supply device, the test is carried out.

The flow valves and other valves are equipped to control the flow rate and get the tested velocity of the piston. The pressure control valves adjust the pressure of outlet oil. When the adjustment is completed, the backpressure remains a constant.

After adjusting the backpressure, the pressure and flow of oil are adjusted by the oil supply device. The oil pressure is set from $2 \mathrm{MPa}$ to $12 \mathrm{MPa}$ in order to avoid the zero drift and linearity of low oil pressure. The oil pressure and displacement of the tested cylinder and the balanced cylinder are recorded by LabVIEW software.

4.2.2. Effect of Oil Pressure on Friction. When the piston of the balanced cylinder moves along the cylinder under oil pressure, friction resistance is produced. The higher the pressure is, the greater the resistance is. In Table 1, the parameters of the Leuven friction model are obtained by adjusting the oil pressure.

Figures 16-19 show the influence of pressure variation on maximum static friction, critical velocity, Coulomb friction, and viscous friction coefficient, respectively. The relationship between $F_{\mathrm{s}}, v_{\mathrm{s}}, F_{\mathrm{c}}, K_{\mathrm{v}}$, and $p$ can be described as equation (17) by MATLAB linear fitting. The friction 


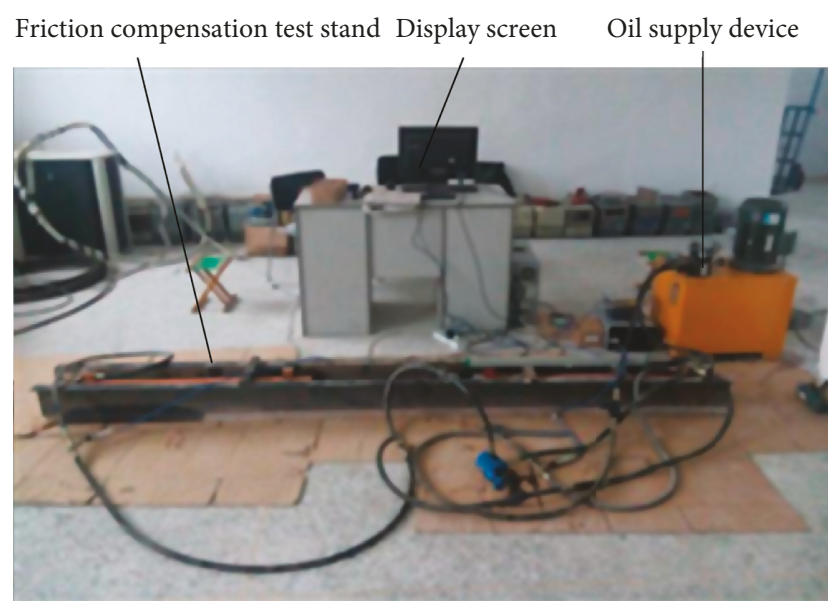

FigURE 15: Friction test rig.

TABle 1: Parameters of the Leuven friction model.

\begin{tabular}{lcccc}
\hline $\begin{array}{l}\text { Oil } \\
\text { pressure }\end{array}$ & $\begin{array}{c}\text { Coulomb } \\
\text { friction }\end{array}$ & $\begin{array}{c}\text { Maximum } \\
\text { static } \\
\text { friction }\end{array}$ & $\begin{array}{c}\text { Stribeck } \\
\text { critical } \\
\text { speed }\end{array}$ & $\begin{array}{c}\text { Viscous } \\
\text { friction } \\
\text { coefficient }\end{array}$ \\
\hline 2 & 0.0799 & 0.1771 & 7.8386 & 0.0013 \\
3 & 0.1095 & 0.1993 & 6.1813 & 0.0014 \\
4 & 0.1331 & 0.2360 & 6.7047 & 0.0015 \\
5 & 0.1557 & 0.2578 & 6.0063 & 0.0015 \\
6 & 0.1813 & 0.2770 & 5.9152 & 0.0017 \\
7 & 0.2116 & 0.2983 & 5.5787 & 0.0017 \\
8 & 0.2368 & 0.3279 & 5.2612 & 0.0017 \\
9 & 0.2584 & 0.3586 & 4.7855 & 0.0018 \\
10 & 0.2963 & 0.3809 & 4.3099 & 0.0019 \\
11 & 0.3356 & 0.4093 & 4.1943 & 0.0019 \\
12 & 0.3192 & 0.4277 & 3.4387 & 0.0020 \\
\hline
\end{tabular}

compensation can be obtained by substituting equation (17) into equation (18):

$$
\begin{gathered}
\left\{\begin{array}{l}
F_{\mathrm{c}}=0.0357+0.0254 p, \\
F_{\mathrm{s}}=0.1276+0.0253 p, \\
v_{\mathrm{s}}=8.3503-0.3966 p, \\
K_{\mathrm{v}}=0.001208+0.00006 p,
\end{array}\right. \\
F(v)=\left[F_{c}+\left(F_{s}-F_{c}\right) e^{-\left(v / v_{s}\right)^{2}}\right] \operatorname{sgn}(v)+K_{v} v .
\end{gathered}
$$

\section{Field Test of Wire Rope Tension and Load Measurement under Compensation}

5.1. Monitoring System and Compensation for Wire Rope Tension and Load. In Figure 20, it can be seen that the monitoring system for wire rope tension and load is mainly composed of signal detection, signal transmission, signal acceptance, signal processing, and monitoring computer. Collected signals are processed and

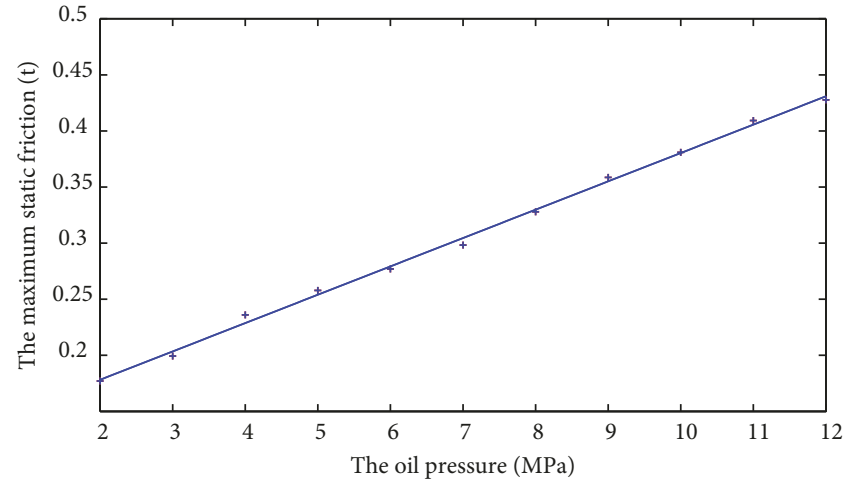

Figure 16: Effect of pressure change on the maximum static friction force.

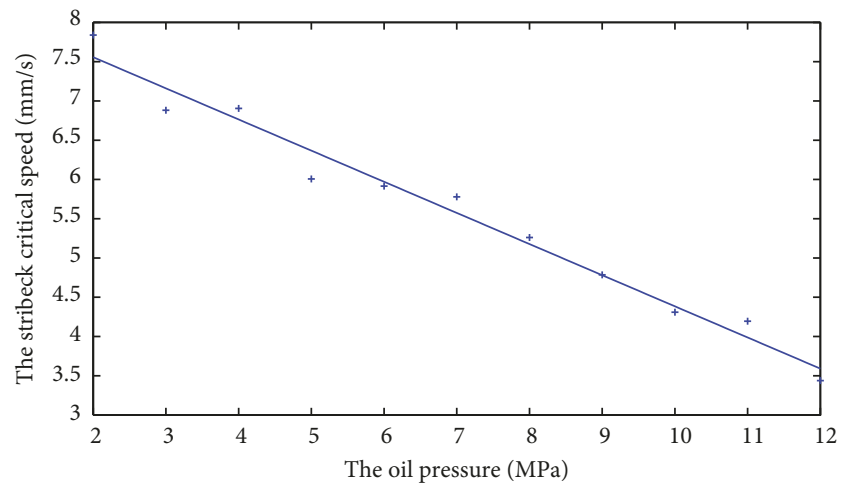

FIGURE 17: Effect of pressure change on the Stribeck critical speed.

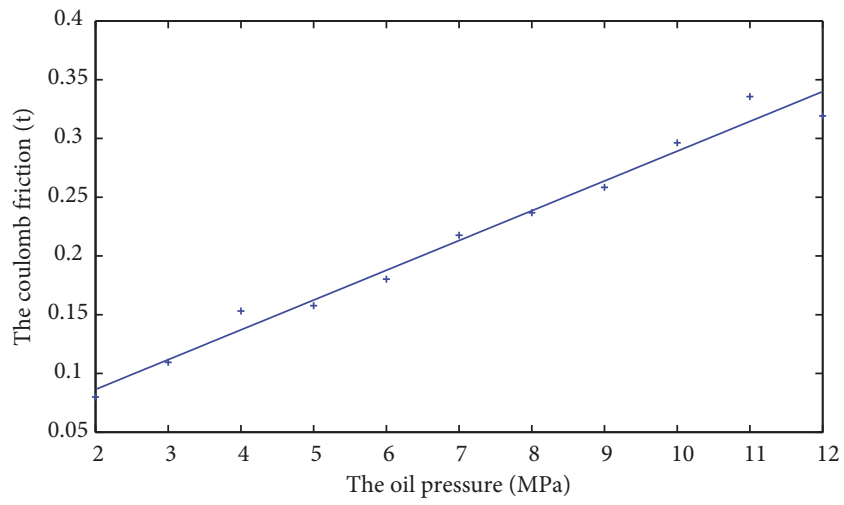

FIGURE 18: Effect of pressure change on the Coulomb friction.

analyzed by the LabVIEW software in the monitoring computer. When the hoist is overloaded, the monitoring computer will give sound and light warnings; if the tension of four wire ropes is unbalanced, it will be compensated according to the Leuven friction model, and the compensation scheme is shown in Figure 21. After compensation, the load of the wire rope can be obtained, which is approximately equal to the sum tension of four wire ropes [23]. 


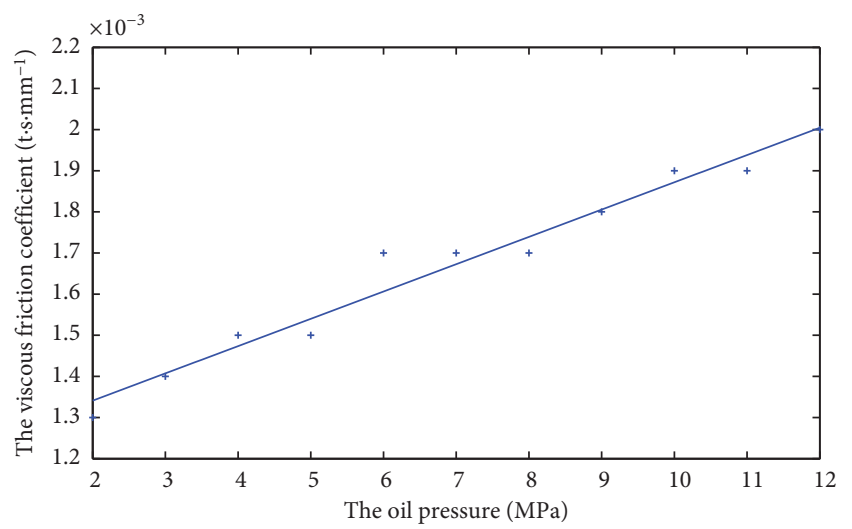

FIGURE 19: Effect of pressure change on the viscous friction coefficient.

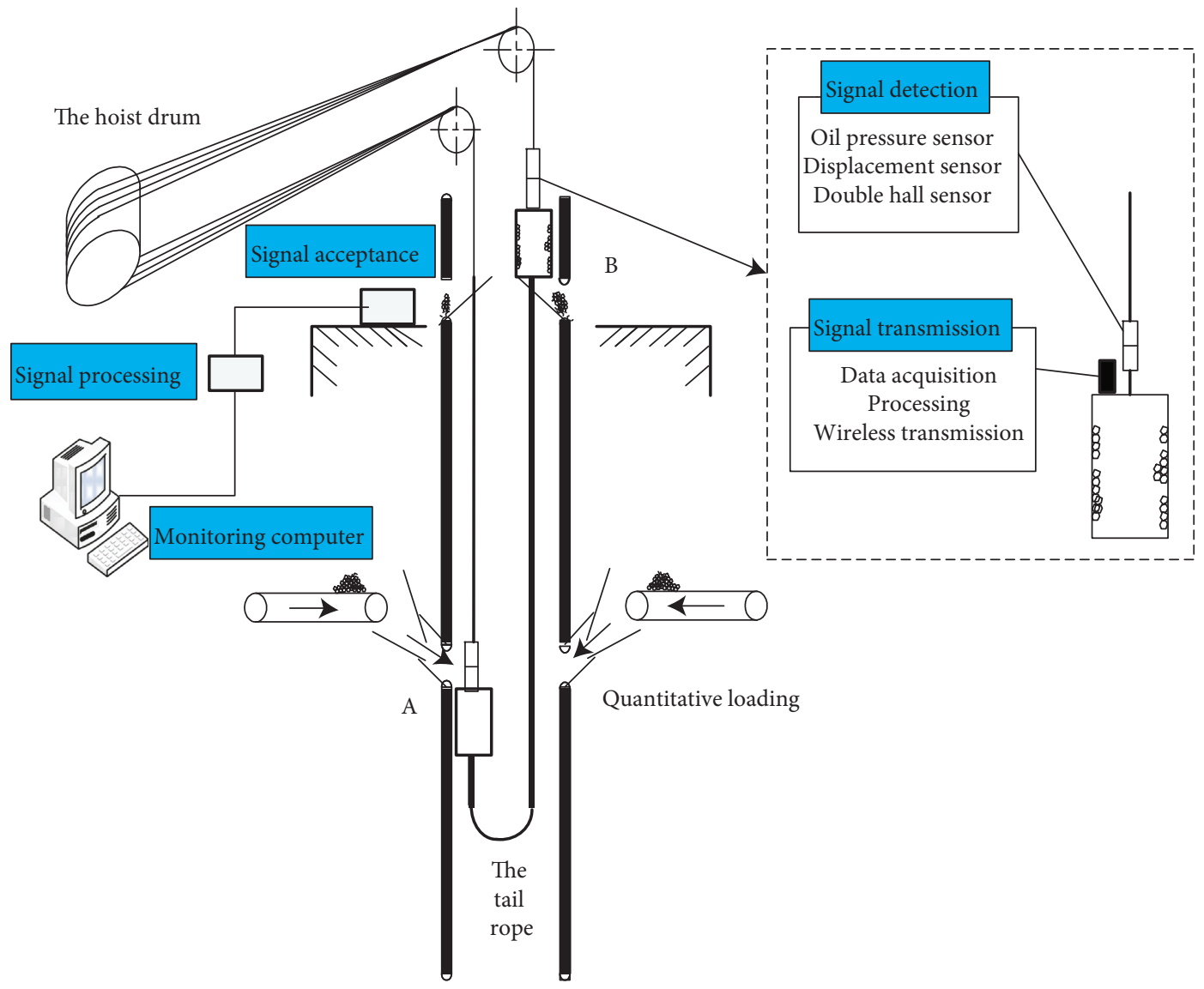

Figure 20: Monitoring system structure of wire rope tension and load.

5.2. Field Test Results of Wire Rope Tension and Load. In order to test the accuracy of measuring the tension and load of wire rope, a field test was carried out in a mine. In Figure 22, it is shown that the hydraulic connecting device is installed in the field. The depth of the mine is $620 \mathrm{~mm}$, the mass of the cage is $8.2 \mathrm{t}$, the number of wire ropes is four, the number of the tail rope is two, and the weight of the tail rope is $6.2 \mathrm{~kg}$ per meter. The data before and after compensation with the Leuven friction model are shown in Table 2. The total load of the hoist is approximately equal to the sum of the tensions of four wire ropes.
It can be seen from the table that the tension at pithead before and after compensation is $145.2 \mathrm{kN}$ and $155.6 \mathrm{kN}$, respectively, and the compensation rate reaches $9.7 \%$.

\section{Conclusion}

Tension and load results measured by oil pressure sensor show that the method can avoid the violent fluctuation of measurement signals of wire rope, but the measurement results are inaccurate due to the loss of oil pressure in the 


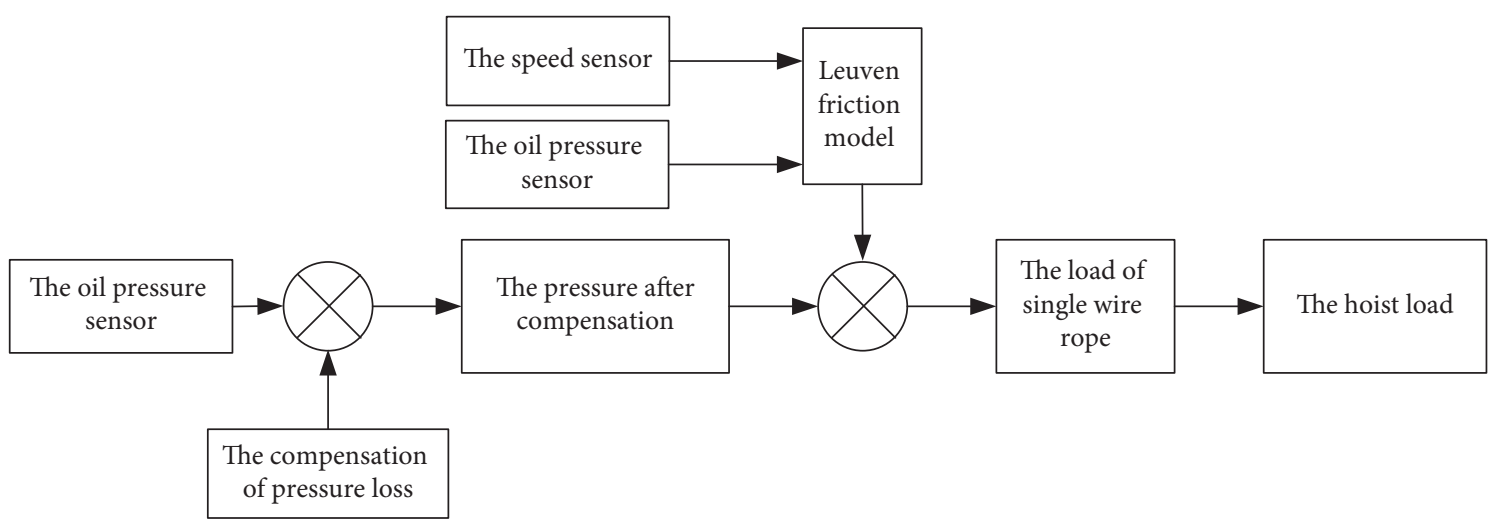

Figure 21: Compensation scheme for wire rope tension and load.

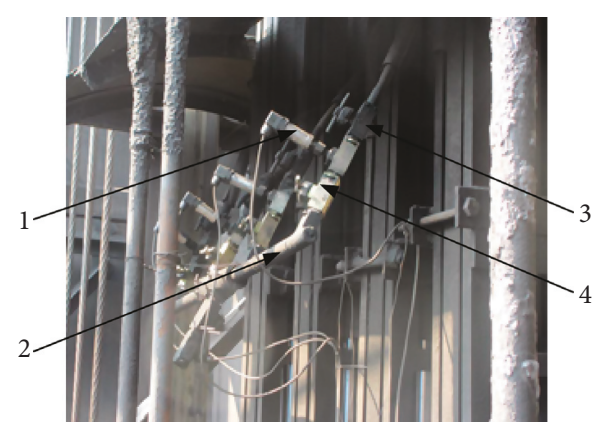

FiguRE 22: The diagrammatic sketch of the on-site installation of oil pressure sensor. 1, oil pressure sensor; 2, connecting pipe; 3 , connector; 4 , globe valve.

TAble 2: Test data.

\begin{tabular}{|c|c|c|c|c|c|c|c|}
\hline \multirow[t]{2}{*}{$\begin{array}{l}\text { Position } \\
\text { of hoist }\end{array}$} & \multirow[t]{2}{*}{$\begin{array}{l}\text { Length of } \\
\text { counterweight } \\
\text { tail rope }(\mathrm{m})\end{array}$} & \multicolumn{2}{|c|}{$\begin{array}{c}\text { Measured value of } \\
\text { sensor nos. } 1,2,3 \text {, and } 4(\mathrm{kN})\end{array}$} & \multicolumn{2}{|c|}{$\begin{array}{l}\text { Sum tension } \\
\text { of four wire } \\
\text { ropes }(\mathrm{kN})\end{array}$} & \multirow[t]{2}{*}{$\begin{array}{l}\text { Total } \\
\text { mass of } \\
\text { hoist }(t)\end{array}$} & \multirow[t]{2}{*}{$\begin{array}{c}\text { Mass of } \\
\text { counterweight } \\
\text { tail rope }(\mathrm{t})\end{array}$} \\
\hline & & Before & After & Before & After & & \\
\hline Pithead & 620 & $34.7,35.1,35.8,36.2$ & $37.8,39.6,39.5,38.7$ & 141.8 & 155.6 & 15.888 & 7.688 \\
\hline Middle of the pit & 300 & $29.6,26.8,28.3,26.5$ & $29.7,30.6,29.3,29.1$ & 111.2 & 118.7 & 11.92 & 3.72 \\
\hline Pit bottom & 20 & $16.8,17.7,16.9,16.7$ & $21.1,20,20.4,21.6$ & 68.1 & 83.1 & 8.448 & 0.248 \\
\hline
\end{tabular}

hydraulic connecting device and the influence of friction force of piston on the cylinder wall.

In this paper, to analyze the impact of friction and pressure loss, the wire rope with the hydraulic connecting device can be regarded as a spring-damper system without mass and the mathematical model is established. The dynamic characteristics of hydraulic cylinder under different pressure and flow rate, the influence of the connecting device on the pressure, and flow rate and speed caused by the load change and pressure impact are analyzed by using AMESim to establish the model and make simulation of the single hydraulic system and hydraulic connection device. The relevant parameters of the Leuven friction model and compensation scheme are obtained by the friction compensation test. The test of the monitoring system and compensation for wire rope tension and load are carried out. The results show that the compensation based on the Leuven friction model improves the accuracy of wire rope tension and load monitoring, which is of great significance for ensuring the safety of the coal mine hoisting system.

\section{Data Availability}

The data used to support the findings of this study are available from the corresponding author upon request.

\section{Conflicts of Interest}

The authors declare that they have no conflicts of interest.

\section{Acknowledgments}

This research was funded by the Priority Academic Program Development (PAPD) of Jiangsu Higher Education Institutions and Jiangsu Engineering Technology Research 
Center on Intelligent Equipment for Fully Mining and Excavating.

\section{References}

[1] X. Li, Z.-C. Zhu, and G. Shen, "A switching-type controller for wire rope tension coordination of electro-hydrauliccontrolled double-rope winding hoisting systems," Proceedings of the Institution of Mechanical Engineers, Part I: Journal of Systems and Control Engineering, vol. 230, no. 10, pp. 1126-1144, 2016.

[2] H. Li, D. Harada, N. Hanajima et al., "Application and performance evaluation of a lifting device with alternating rotation hoist," in Proceedings of the 2016 IEEE/SICE International Symposium on System Integration (SII), IEEE, Kobe, Japan, December 2016.

[3] G. L. Zhou and W. J. Chu, "The influence of the leading wheel structural change on stress of multi-rope friction hoist," Advanced Materials Research, vol. 670, pp. 48-53, 2013.

[4] X. Teng, J. Chen, and M. Tang, "The current situation and application for hoist load monitoring researching," Coal Mine Machinery, vol. 6, pp. 5-7, 2008.

[5] C. Mitsantisuk, K. Ohishi, and S. Katsura, "Control of interaction force of twin direct-drive motor system using variable wire rope tension with multisensor integration," IEEE Transactions on Industrial Electronics, vol. 59, no. 1, pp. 498-510, 2012.

[6] S. Daifuku, B. Li, Y. Yamaguchi, M. Nagatoshi, and K. Imado, "Development of tension meter for wire rope and lashing belt," Journal of Mechanical Systems for Transportation and Logistics, vol. 6, no. 1, pp. 65-72, 2013.

[7] Y. Jian and G. Wang, "The method of Tension balance for wire rope of multi rope friction hoist," Coal Mine Machinery, vol. 1, pp. 192-193, 2009.

[8] X. Zhang and H. Jin, "Design of strain tension sensor of steel wire rope used in the coal mine," in Proceedings of the Seventh International Symposium on Precision Mechanical Measurements, p. 99030C, Xiamen, China, January 2016.

[9] P. Liu, X. Zhang, Y. K. Huang, and J. X. Rong, "The analysis of wire rope tension sensor elastic body based on solidworks," Advanced Materials Research, vol. 591-593, pp. 1603-1606, 2012.

[10] M. K. Singh, A. Mahto, R. N. Thakur, and A. Sinha, "Failure analysis of wire rope used for hoisting in mining: a case study," Journal of Failure Analysis and Prevention, vol. 7, no. 2, pp. 87-91, 2007.

[11] M. J. O'Dogherty, "The design of octagonal ring dynamometers," Journal of Agricultural Engineering Research, vol. 63, no. 1, pp. 9-18, 1996.

[12] H. W. Jin and X. Zhang, "Design of dynamic tension detection system of multi-hoisting wire rope," Applied Mechanics and Materials, vol. 201-202, pp. 565-568, 2012.

[13] Y. Zhang and H. Z. Sun, "Analysis and design of Hoist wire rope tension monitoring system," Advanced Materials Research, vol. 971-973, pp. 364-367, 2014.

[14] D. Fan and Z. Yang, "Test method of hoist wire-rope tension based on inhomogeneous chord vibration," Meitan Xuebao/ Journal of the China Coal Society, vol. 35, no. 5, pp. 840-843, 2010.

[15] S. J. Wang, Z. J. Yang, and F. Du, "Study on the method of multi-rope hoist rope tension imbalance fault monitoring and diagnosis," Advanced Materials Research, vol. 139-141, pp. 2591-2594, 2010.
[16] L. Tan, "The design of hositing load monitoring device of mine," Industry and Mine Automation, vol. 36, no. 12, pp. 81-83, 2010.

[17] V. Lampaert, J. Swevers, and F. Al-Bender, "Modification of the Leuven integrated friction model structure," IEEE Transactions on Automatic Control, vol. 47, no. 4, pp. 683687, 2002.

[18] B. D. Jing, S. Lu, L. Z. Yang, and H. Wu, "Research of hydraulic jack leakage diagnosis emulation base on wavelet/ AMESim," Key Engineering Materials, vol. 392-394, pp. 103-108, 2009.

[19] W. Marquis-Favre, E. Bideaux, and S. Scavarda, "A planar mechanical library in the AMESim simulation software: part I-formulation of dynamics equations," Simulation Modelling Practice and Theory, vol. 14, no. 1, pp. 25-46, 2006.

[20] W. Wang, X. Fu, and H. Xie, "The modeling of AMESim based hydraulic parallel mechanism and simulation of its coupling characteristics," Journal of Zhejiang University (Engineering Science), vol. 41, no. 11, pp. 75-80, 2007.

[21] Z. Jiang, S. Xu, D. Gu, and Y.-L. Xia, "Research on friction compensation based on interval analysis theory," Optical Precision Engineering, vol. 25, no. 6, pp. 1519-1525, 2017.

[22] D. Yuan, L. Liu, H. Liu, Z Wu, and Z Wang, "Research status of sliding friction model," Journal of Systems Simulation, vol. 21, no. 4, pp. 1142-1147, 2009.

[23] T. Shi, P. Wang, and B. Wang, "The design of wire rope tension monitoring system of mine hoist," Industry and Mine Automation, vol. 40, no. 6, pp. 103-105, 2014. 


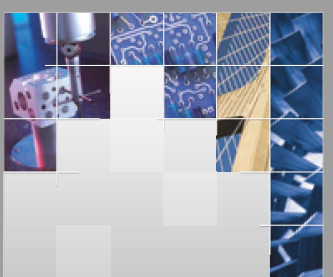

\section{Enfincering}
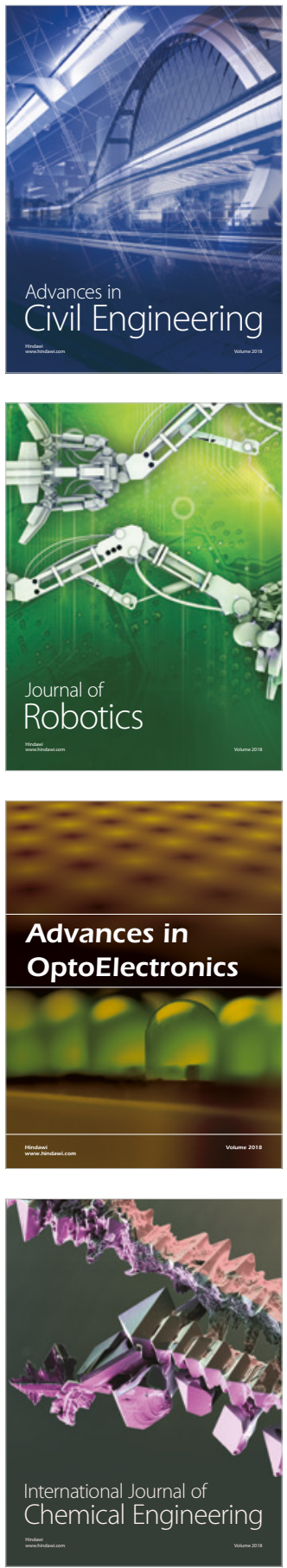

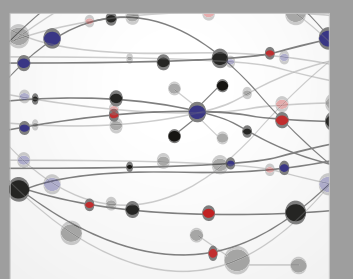

\section{Rotating \\ Machinery}

The Scientific World Journal

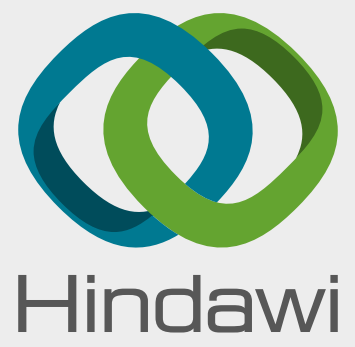

Submit your manuscripts at

www.hindawi.com
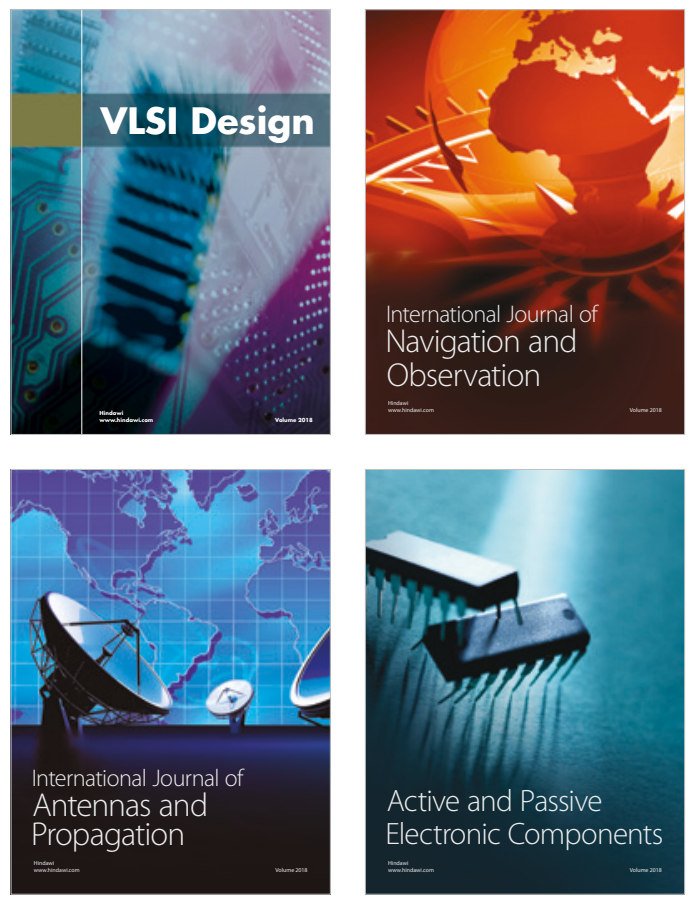
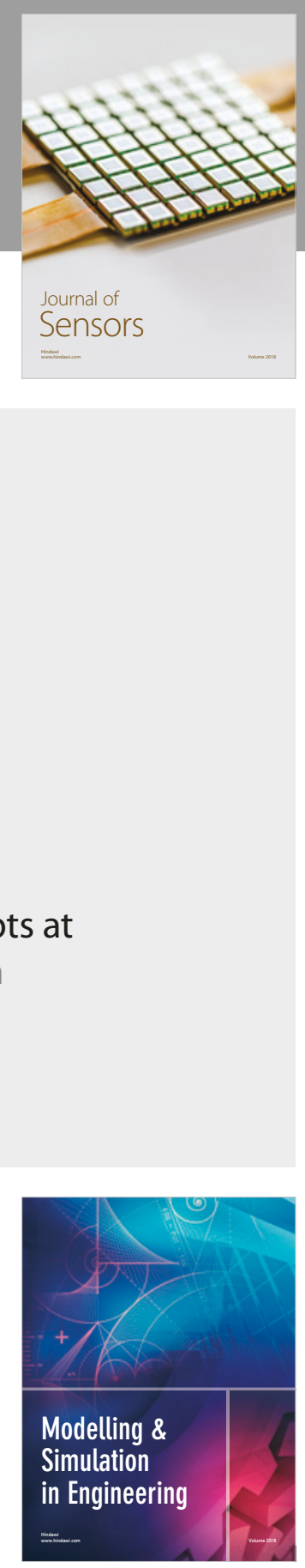

\section{Advances \\ Multimedia}
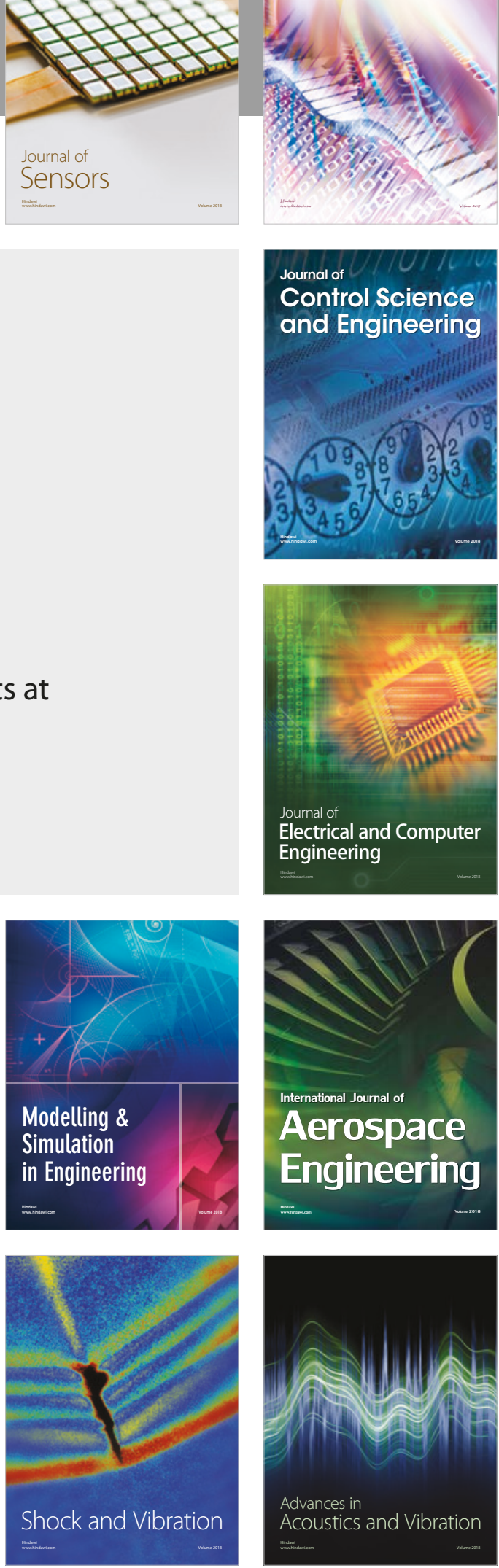